\title{
Unpronounceable drug names
}

\section{Craig Patterson}

Editor, Australian Medicines Handbook, Adelaide

\section{Keywords}

medication errors, drug names, drug information

Aust Prescr 2018;41:176-7 https://doi.org/10.18773/ austprescr.2018.057
"Pot-ay-toe, pot-ah-toe. Tom-ay-toe, tom-ah-toe. Let's call the whole thing off."

Songwriters George and Ira Gershwin understood the problem of different pronunciations of the same word way back in 1937. At that time, the only patented medicines doctors had to know how to pronounce were aspirin, insulin, penicillin, phenobarbital and sulfanilamide. Today's prescribers are confronted by ixekizumab, rovalpituzumab, tofacitinib and idelalisib.

Conspiracy theorists might suggest that the generic name of a drug is intentionally unpronounceable to facilitate the use of its brand name in conversation. There is an agreed system to naming biologic drugs,' however, apart from the length of their names, a major problem is that they often combine strings of letters that have no equivalent in the English language. ${ }^{2}$ We therefore have no reference points to help us with the pronunciation.

Some may say that such uncertainty around how to pronounce drug names is not a significant problem, especially in the age of electronic prescribing. The problem of lookalike and soundalike drug and brand names is well recognised, ${ }^{1}$ but there is an evidence gap regarding any impact that mispronunciation may have on patient safety. There are many instances where verbal communication remains at the core of drug transactions between health professionals and with their patients. Telephone orders between prescribers, ${ }^{3}$ clinical handovers, voice-recognition software and text-to-speech systems are all situations where misunderstanding could result in the wrong drug being given. ${ }^{4,5}$ The problem is amplified by unfamiliarity when all you have heard is blah-dee-blah-mab.

The first time I heard someone say cloppy-DOG-rel (clopidogrel), I was taken aback. It had never occurred to me to pronounce the drug in this way, but how should Australians say this word?

The pharmaceutical company, which markets a new drug, knows how to talk about its product. The drug has been nursed through clinical trials and given an accepted, non-proprietary name. When the company's representatives promote the drug they introduce the new name with its preferred pronunciation. However, not everyone gets a visit from a drug company representative and the focus is often on more mellifluous brand names. Sometimes, names end up with a life of their own and before you know it, klo-PIDD-oh-grell is cloppy-DOG-rel.
In 2003, the then National Prescribing Service (NPS) commenced its work on contextualising the role of new drugs on the Pharmaceutical Benefits Scheme with the Rational Assessment of Drugs and Research (RADAR) publication. One of the ideas for RADAR recognised that, as the new drug name would be unfamiliar to health professionals, it would be useful to publish a phonetic spelling of the generic drug name to aid pronunciation. This dovetailed with other NPS messages, directed to consumers, that they be familiar with the generic name of their medicines and not just the brand names.

What seemed an unambitious goal - to source pronunciations of drug names - turned out to be particularly difficult. Australian product information never includes a pronunciation guide. While Consumer Medicines Information (CMI) does include pronunciation tips occasionally, the coverage is extremely patchy and, surprisingly, there can be inconsistencies. The CMI for Iscover suggests that clopidogrel is pronounced klo-PIDD-oh-grell, while the CMI for DuoCover suggests clop-id-o(h)-grel. Both products are marketed in Australia by the same company.

As with most things, the Internet will give you all the variation that might exist on a topic and is therefore of limited reliability. For example, more than one website suggested the cholesterol-lowering drug, ezetimibe, be pronounced e-zet-e-mib, with a short suffix that could easily be confused with the biologic drug suffix $i b$.

In the end, RADAR was able to use the American Medical Association's Dictionary of United States Adopted Names (https://www.ama-assn.org/ about-us/adopted-names) as a starting point for how the drug might be pronounced. However, the pronunciation requires a familiarity with the arcane use of diacritical marks, and thus needs to be used in conjunction with a key to pronunciation (https://www.ama-assn.org/pronunciation-guide).

The question is - can we rely on North American interpretations when Australian speech patterns are so very different? A case in point is dabigatran. A recent US commentary asserted the drug is pronounced da bye gat' ran. ${ }^{2}$ The long 'i' immediately attracted my attention as being a regional difference unlikely to be repeated in Australia: think sem-eye final (semi-final) or ant-eye-bye-o-tic (antibiotic). 
So what can we do? Free online sources such as Drugs.com (https://www.drugs.com/drug information.html) and ClinCalc.com (http://clincalc.com/ pronouncetop200drugs) provide pronunciation examples, notwithstanding the North American accents. Other sources are available, but sit behind paywalls.

At a local level, in the same way there was a move to include the active ingredient as prominently as the brand name on labelling, perhaps a groundswell could begin to systematically include phonetic pronunciation of the generic drug name in the CMI. Additionally, just as the product information and CMI for a drug can be found on the website of the Therapeutic Goods Administration, perhaps an audio file with the correct pronunciation could be included. This audio file should be a human spoken voice, not a digitised voice typical of text-to-speech systems.

These easily achievable solutions could mitigate the problem immortalised by the Gershwins and have us all singing from the same song sheet.

Craig Patterson is a former editor of NPS RADAR.

\section{REFERENCES}

1. Drugs and their names. Drug Ther Bull 2018;56:33-6. https://doi.org/10.1136/dtb.2018.3.0602

2. Frank DS. I'm talking to you-mab - how to pronounce the new, unpronounceable pharmaceuticals. JAMA Intern Med 2018;178:319-20. https://doi.org/10.1001/ jamainternmed.2017.7898

3. Pronunciation of drug names. Drug Ther Bull 1970;8:32. https://doi.org/10.1136/dtb.8.8.32
4. Henton C. Bitter pills to swallow: ASR and TTS have drug problems. Int J Speech Technol 2005;8:247-57. https://doi.org/10.1007/s10772-006-5889-0

5. Travers R. Terry's parrot died: adventures in voice recognition. Med J Aust 2017;207:495. https://doi.org/ $10.5694 / \mathrm{mja17} .00738$ 